\section{Early In-Stent Restenosis Due to Delayed Protrusion of Underlying Atheromatous Plaque}

Munemitsu Otagaki, MD; Koichiro Matsumura, MD; Kenichi Fujii, MD; Hiromi Kin, MD;

Yoshihiro Yamamoto, MD; Ichiro Shiojima, MD

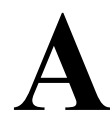
n 81-year-old man underwent percutaneous coronary intervention in the left circumflex coronary artery with 2 third-generation drug-eluting stents (Supplementary Figure A-C). Final intravascular ultrasound showed neither tissue protrusion nor malapposition (Supplementary Figure D). The patient was maintained on dual-antiplatelet therapy with aspirin and prasugrel. One month later, repeat coronary angiogram showed an $80 \%$ stenosis in the middle of the stents (Figure A). Optical coherence tomography (OCT) indicated a high-backscattering protruding mass with an irregular surface in the stent (Figure B; Supplementary Movie). Manual aspiration was attempted, and the mass was successfully removed. On histology the mass consisted of cholesterin crystals, foam cells, and necrotic debris (Figure C). Histological analysis confirmed that the removed tissue consisted of atheromatous materials. Neoatherosclerosis has previously been shown to develop in the late phase ( $>3$ years) after stenting. ${ }^{1}$ Therefore, a potential mechanism for the acute development of atherosclerotic tissue early after stenting may be delayed protrusion of the underlying necrotic core beyond the stent struts into the lumen.

\section{Disclosures}

The authors declare no conflicts of interest.

\section{Reference}

1. Nakazawa G, Otsuka F, Nakano M, Vorphal M, Yazdani SK, Ladich E, et al. The pathology of neoatherosclerosis in human coronary implants bare-metal and drug-eluting stents. $\mathrm{J} \mathrm{Am} \mathrm{Coll}$ Cardiol 2011; 57: 1314-1322.

\section{Supplementary Files}

Supplementary Movie. Optical coherence tomography pull-back before the second treatment.

Please find supplementary file(s);

http://dx.doi.org/10.1253/circj.CJ-18-1248

Received December 2, 2018; revised manuscript received January 11, 2019; accepted January 27, 2019; J-STAGE Advance Publication released online March 9, 2019 Time for primary review: 37 days

Department of Cardiology, Kansai Medical University Medical Center, Moriguchi (M.O., K.M., H.K., Y.Y.); Division of Cardiology, Department of Medicine II, Kansai Medical University, Hirakata (K.F., I.S.), Japan

Mailing address: Koichiro Matsumura, MD, Department of Cardiology, Kansai Medical University Medical Center, 10-15 Fumizono-cho, Moriguchi 570-8507, Japan. E-mail: kmatsumura1980@yahoo. co.jp

ISSN-1346-9843 All rights are reserved to the Japanese Circulation Society. For permissions, please e-mail: cj@j-circ.or.jp
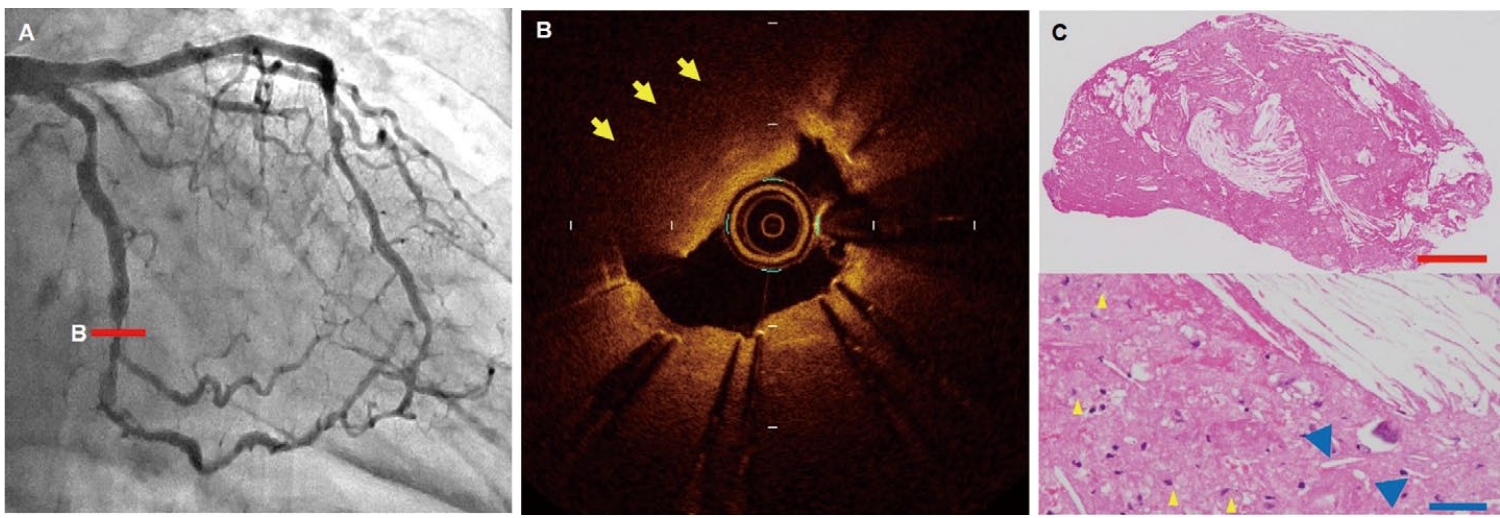

Figure. (A) Angiography 1 month after stenting showing early restenosis. (B) Optical coherence tomography indicating a highbackscattering protruding mass (arrows). (C) Histology of the detached protruding tissue, which was composed of atheromatous materials. The mass contained cholesterin crystals (blue arrowheads), foam cells (yellow arrowheads), and necrotic debris. Red scale bar, $500 \mu \mathrm{m}$; blue scale bar, $50 \mu \mathrm{m}$. 